\title{
Fast and reliable PCR/sequencing/RFLP assay for identification of fungi in onychomycoses
}

\begin{abstract}
Correspondence
Michel Monod

Michel.Monod@chuv.ch
\end{abstract}

Received 15 May 2006

Accepted 30 May 2006

\author{
Michel Monod, Olympia Bontems, Christophe Zaugg, Barbara Léchenne, \\ Marina Fratti and Renato Panizzon
}

\author{
Department of Dermatology, Centre Hospitalier Universitaire Vaudois, CH-1011 Lausanne, \\ Switzerland
}

\begin{abstract}
Fusarium spp. and other non-dermatophyte fungi are repeatedly isolated from abnormal nails. To investigate whether these fungi are the aetiological agents of infection or simply transient contaminants, a PCR/sequencing/RFLP assay was developed for direct and routine identification of the infecting fungi in onychomycosis. Fungal DNA was readily extracted using a commercial kit after dissolving nail fragments in a $\mathrm{Na}_{2} \mathrm{~S}$ solution. Amplification of part of the $28 \mathrm{~S}$ rDNA by PCR was performed with universal primers and the fungal species were identified by sequencing. The PCR/sequencing results were comparable with microbiological identification from the same nail sample. In addition to dermatophytes, Fusarium spp. and other less frequently isolated non-dermatophyte fungi were identified as single fungal agents in onychomycosis. Moreover, mixed infections were clearly demonstrated in $10 \%$ of cases by RFLP analysis of PCR products. Identification of infectious agents could be obtained in 2 days, whilst results from fungal cultures take 1-3 weeks. Rapid and reliable molecular identification of the infectious fungus expedites the choice of appropriate antifungal therapy, thereby improving the cure rate of onychomycosis.
\end{abstract}

\section{INTRODUCTION}

Onychomycosis is the most prevalent nail disease (Chabasse, 2004). Direct microscopic examination of infected nail material should confirm a clinical diagnosis of fungal infection whenever possible before oral treatment is commenced. Subsequent fungal culture from nail sampling permits the species involved in the infection to be determined. Onychomycoses are mainly caused by dermatophytes, but various non-dermatophyte filamentous fungi (NDF) are often isolated from abnormal nails (Summerbell et al., 2005). Repeated isolations of the same NDF permit us to conclude with some certainty their involvement in nail infection (English, 1976; Gupta et al., 2001a; Summerbell et al., 2005). However, whether NDF are really the aetiological agents of onychomycosis or whether they should be considered as casual and transient contaminants often remains an open question. In addition, it is common to obtain negative results from fungal cultures of nail specimens where direct microscopic examination showed fungal elements. This problem frequently occurs with nails of patients already being treated with antifungal therapy. In all cases, correct identification of the aetiological agent of nail infections is necessary to identify the appropriate treatment, as NDF are weakly responsive or unresponsive to

Abbreviations: LSU, large subunit; NDF, non-dermatophyte filamentous fungi. certain antifungal drugs (Tosti et al., 2000; Gupta et al., 2001b; Garcia-Effron et al., 2004).

Direct identification of the infecting agent in the nail has been shown to be feasible using PCR and RFLP. Different investigations have focused mainly on the identification of dermatophytes and Scytalidium spp. (Baek et al., 1998; Turin et al., 2000; Machouart-Dubach et al., 2001; Menotti et al.; 2004; Kardjeva et al., 2006). Here, we report the development of a PCR/sequencing/RFLP assay that was able to identify directly the large number of Fusarium spp. and other NDF that we routinely isolate in culture from abnormal nail samples. The assay was found to be reliable by comparing the results obtained from the sequences of PCR products of extracted fungal DNA with the results of cultures from the same nail sample. We showed that Fusarium spp. and NDF are the aetiological agents of an appreciable percentage of onychomycosis in Switzerland. In addition, mixed infections could be clearly demonstrated by RFLP.

\section{METHODS}

Clinical samples. Nail scrapings and fragments were collected from patients with suspected onychomycosis. Routinely, one part of each sample was examined in nail-dissolving solution containing a fluorochrome (Monod et al., 1989). The reactive solution was prepared by dissolving $1 \mathrm{~g} \mathrm{Na}_{2} \mathrm{~S}$ in $7.5 \mathrm{ml}$ distilled water and subsequently adding $2.5 \mathrm{ml}$ ethanol. Thereafter, $10 \mu \mathrm{l}$ Blankophor $\mathrm{P}$ 
flüssig (Bayer) or $20 \mu \mathrm{l} 1 \%$ aqueous solution of Tinopal UNPA-GX (Fluorescent brightener 28, F3543; Sigma) was added to this mixture. In parallel, another portion of nail sample was seeded in test tubes containing Sabouraud's agar medium with chloramphenicol $\left(50 \mu \mathrm{g} \mathrm{ml}^{-1}\right)$ or with chloramphenicol plus cycloheximide $\left(400 \mu \mathrm{g} \mathrm{ml}^{-1}\right)$. Cultures were incubated at $30^{\circ} \mathrm{C}$. Dermatophytes and moulds were identified after 14-21 days of growth by macroscopic and microscopic examination (Mock et al., 1998; de Hoog et al., 2000). When enough material had been collected, a one-third portion of the nail sample was conserved at room temperature in a dry box for subsequent fungal DNA extraction. Fragments of normal nails from healthy volunteers were used as negative controls.

DNA extraction. Nail scrapings and fragments $(2-30 \mathrm{mg})$ were incubated in a $1.5 \mathrm{ml}$ microcentrifuge tube overnight in $500 \mu \mathrm{l}$ naildissolving solution without fluorochrome. After centrifugation at $5000 \mathrm{~g}$ for $2 \mathrm{~min}$, the sample precipitate containing fungal elements dissociated from keratinocytes was washed twice with distilled water. Subsequently, fungal DNA was extracted using the EZNA Fungal DNA Mini kit (Peqlab Biotechnologie) using the protocol provided by the manufacturer. The DNA was eluted from the disposable spin column with $50 \mu$ distilled water.

PCR and DNA sequencing. PCR was performed under standard conditions using large subunit (LSU) primers (Table 1) to amplify a portion of the $28 \mathrm{~S}$ rDNA as follows. Extracted DNA (3-20 $\mu \mathrm{l})$, $2 \cdot 5 \mu \mathrm{l}$ of each sense and antisense oligonucleotide $(42 \mathrm{mM}), 4 \mu \mathrm{l}$ dNTP mix (10 mM each dNTP) and $5 \mu 110 \times$ PCR buffer $[100 \mathrm{mM}$ Tris/HCl (pH 8.3), $500 \mathrm{mM} \mathrm{KCl}, 15 \mathrm{mM} \mathrm{MgCl}_{2}$ ] were mixed with deionized water to give a total reaction volume of $50 \mu \mathrm{l}$. To each reaction, $2.5 \mathrm{U}$ AmpliTaq DNA polymerase (Perkin Elmer) was added. The reaction mixture was incubated for $1 \mathrm{~min}$ at $94^{\circ} \mathrm{C}$, followed by 40 cycles of $0.5 \mathrm{~min}$ at $94{ }^{\circ} \mathrm{C}, 0.5 \mathrm{~min}$ at $55^{\circ} \mathrm{C}$ and 0.5 min at $72{ }^{\circ} \mathrm{C}$, with extension for $10 \mathrm{~min}$ at $72{ }^{\circ} \mathrm{C}$.

PCR amplicons and restriction enzyme digestion products ranging from 100 to $350 \mathrm{bp}$ were loaded on $1 \cdot 5 \%(\mathrm{w} / \mathrm{v})$ agarose gels (TBE buffer) in the presence of ethidium bromide $\left(0 \cdot 5 \mu \mathrm{g} \mathrm{ml}^{-1}\right)$. DNA molecular mass marker XIV (100 bp ladder; Roche) was added. After running for $1 \mathrm{~h}$ at $6 \mathrm{~V} \mathrm{~cm}^{-1}$, DNA fragments were visualized with UV light $(300 \mathrm{~nm})$ and recorded photographically.

For sequencing, amplified DNA was treated with exonuclease I (Fermentas Life Sciences) to digest the original primers and with alkaline phosphatase (Fermentas Life Sciences) to dephosphorylate free nucleotides for $15 \mathrm{~min}$ at $37^{\circ} \mathrm{C}$. Enzymes were heat-inactivated $\left(15 \mathrm{~min}\right.$ at $\left.80^{\circ} \mathrm{C}\right)$. DNA sequencing was performed by Synergene Biotech (Switzerland) on an automated ABI PRISM 3100 DNA Sequencer (Applied Biosystems). The rDNA sequences were aligned using CLUSTAL_X version 1.8 and annotated by BLAST on a nonredundant database.
Table 2. Prevalence of different fungi in nail specimens analysed by direct mycological examination in Lausanne University Hospital from 2003 to 2005

\begin{tabular}{|lrrr|}
\hline & Positive & Negative & Total \\
\hline Dermatophytes & 879 & 12 & 891 \\
Fusarium spp. & 128 & 13 & 141 \\
Aspergillus spp. & 119 & 24 & 143 \\
S. bevicaulis & 51 & 6 & 57 \\
Candida spp. & 362 & 178 & 540 \\
Other NDFs & 760 & 541 & 1301 \\
Negative fungal culture & 1515 & 2260 & 3775 \\
Total & 3814 & 3034 & 6848 \\
\hline
\end{tabular}

\section{RESULTS AND DISCUSSION}

\section{Fungi isolated from nail specimens}

During a 3 year period (2003-2005), the total number of abnormal nail samples sent for mycological analysis was 6848 (Table 2). When fungal elements were detected by direct mycological examination (positive samples), only $23 \%$ of nail cultures revealed dermatophyte infection. Trichophyton rubrum was the most frequently isolated dermatophyte with a prevalence of $81 \%$. Trichophyton mentagrophytes was identified in $18 \%$ of the cases. Rare dermatophytes were Trichophyton soudanense (four cases), Epidermophyton floccosum (one case) and Microsporum audouinii (one case). Fusarium spp. cultures were obtained with a significant frequency from positive nail samples $(4 \%)$. The numbers of dermatophytes and other fungi, such as Scopulariopsis brevicaulis and Fusarium spp., obtained from samples that did not show any fungal elements (negative samples) were low in accordance with previous studies (Baudraz-Rosselet et al., 1992). The use of fluorescence microscopy reduced the risk of not observing fungi in direct mycological examinations. Fungal spores and hyphae produced bright fluorescence, which is easily detected even in specimens with few fungi (Monod et al., 1989).

\section{Identification of infecting fungi in nail samples by PCR}

DNA was extracted from nail samples that showed fungal hyphae or spores by direct mycological examination. After 2-6 h incubation in $\mathrm{Na}_{2} \mathrm{~S}$ nail-dissolving solution, fungal

Table 1. Primers used in this study

LSU2 was used as the antisense primer for all PCRs.

\begin{tabular}{|llll|}
\hline Primer & \multicolumn{1}{c}{ Sequence $\left(\mathbf{5}^{\prime} \rightarrow \mathbf{3}^{\prime}\right)$} & \multicolumn{1}{c|}{ Target } & Fragment size (bp) \\
\hline LSU1 & GATAGCGMACAAGTAGAGTG & Dermatophyte and NDF 28S rDNA & $310-314$ \\
LSU2 & GTCCGTGTTTCAAGACGGG & Dermatophyte and NDF 28S rDNA & - \\
FUS & TGACCAGACTTGGGCTTGG & Fusarium spp. 28S rDNA & 221 \\
CAND & GGGCTTGAGATCAGACTTGG & Candida spp. 28S rDNA & 230 \\
\hline
\end{tabular}


Table 3. Results of PCR (fragment sequencing and RFLP) analysis versus morphological identification of fungi isolated from nail specimens

All tested samples were positive for fungal elements after direct mycological examination. M, mixed infection; NI, not identified.

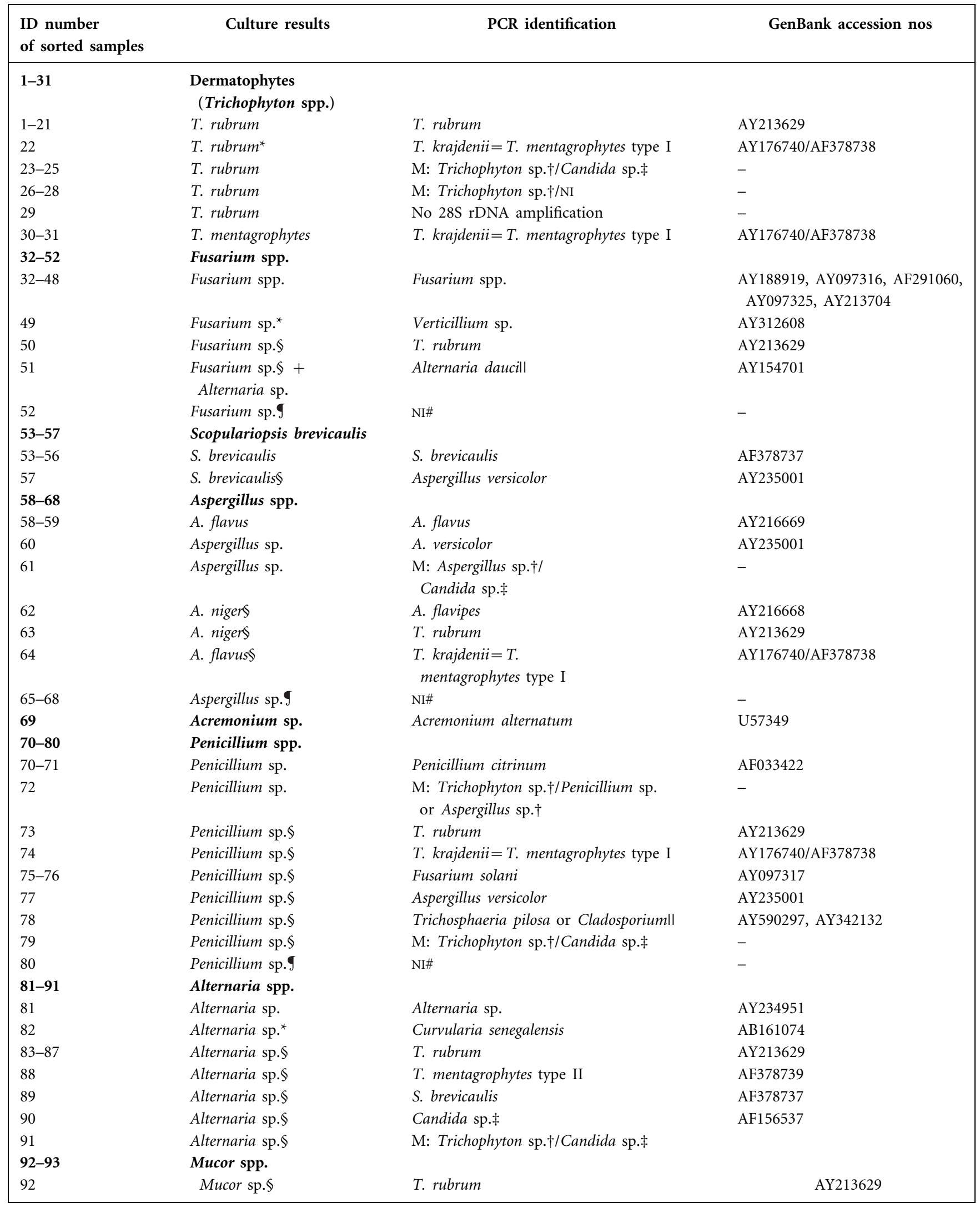


Table 3. cont.

\begin{tabular}{|c|c|c|c|}
\hline $\begin{array}{l}\text { ID number } \\
\text { of sorted samples }\end{array}$ & Culture results & PCR identification & GenBank accession nos \\
\hline 93 & Mucor sp. & M. circinelloides & AY213710 \\
\hline $94-97$ & & T. rubrum & AY213629 \\
\hline 98 & & T. mentagrophytes type II & AF378739 \\
\hline $99-100$ & & Fusarium acutatum & AY213704 \\
\hline 102 & & Aspergillus flavus & AY235016 \\
\hline 103 & & Aspergillus versicolor & AY235001 \\
\hline 104 & & Emericella quadrilineata & AY213696 \\
\hline 105 & & Pleospora papaveracea or Alternaria spp.II & AY152615 \\
\hline 106 & & $\mathrm{M}:$ T. rubrum/NI & - \\
\hline 110 & C. parapsilosis & C. parapsilosis & AY497686 \\
\hline 111 & C. albicans & M: C. albicans/NI & AY233747 \\
\hline
\end{tabular}

${ }^{\star}$ Probable mis-identification.

$\dagger$ Identification by RFLP only.

$\ddagger$ PCR positive using CAND primers (Table 2).

\$Probable contaminant.

IIUncertain identification due to poor-quality sequence.

SUncertain aetiological agent.

\#Weak amplification and uninterpretable sequencing results (seven samples).

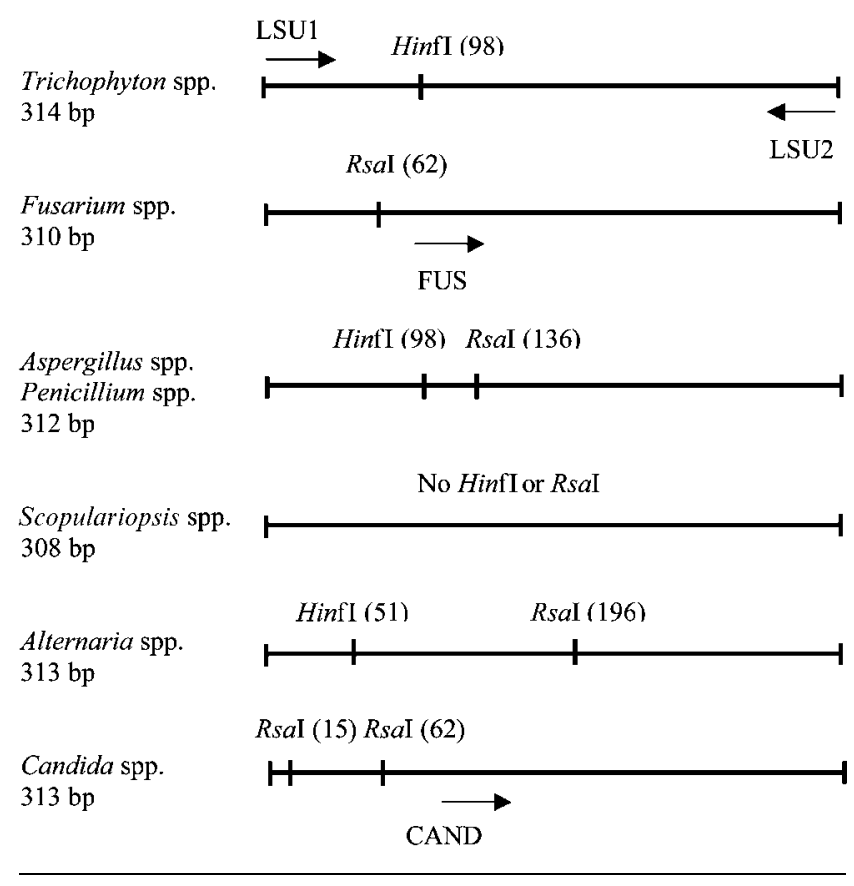

Fig. 1. Rsal and Hinfl restriction maps of amplified DNA for the most prevalent fungi in onychomycosis. The primers in Table 1 are indicated by horizontal arrows. elements were totally dissociated from keratinocytes. A quantity of 50-550 ng DNA in a volume of $50 \mu \mathrm{l}$ could be extracted from nail samples of $2-30 \mathrm{mg}$. PCR was performed as described in Methods using primers LSU1 and LSU2 (Table 1). Each PCR included Saccharomyces cerevisiae DNA as a positive control and no DNA as a negative control. PCR results were visualized on agarose gels and no PCR products were obtained from normal, uninfected nails. The DNA extraction method used was simple and presented several advantages: (i) nail samples were processed in a single test tube before extraction of the DNA on a spin column; (ii) mechanical homogenization or shearing of the nail fragment was not required; and (iii) treatment with large amounts of lyticase and proteinase $\mathrm{K}$ was not required. DNA from 20 samples could be extracted simultaneously using a bench-top microcentrifuge.

Positive PCR products (15 ng) were sent for sequencing. First, we identified the infecting fungi in samples from which Fusarium spp. and dermatopytes were obtained in culture (samples 1-52; Table 3 ). The PCR results agreed with those of classical mycological identification in 17/21 cases for Fusarium spp. Three PCR products (samples 49-51; Table 3) revealed Verticillium sp., T. rubrum and Alternaria dauci after sequencing. T. rubrum was found in 

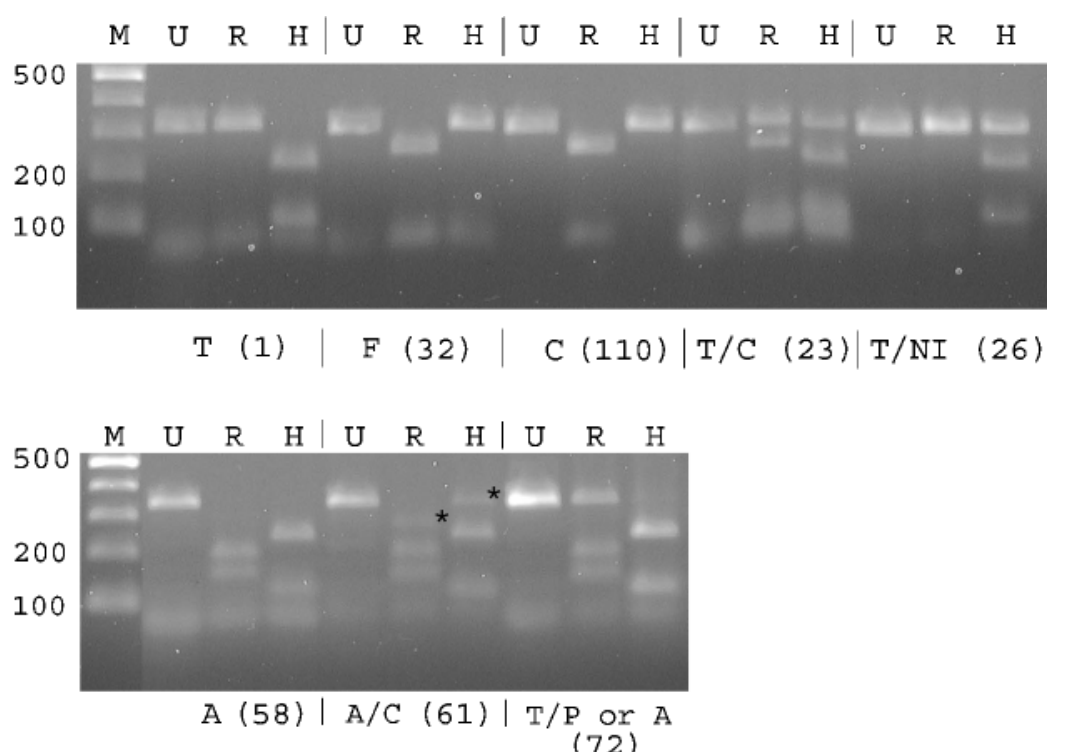

(72)
Fig. 2. Amplification and RFLP gels of DNA extracted from human onychomycosis samples. M, 100 bp ladder; U, undigested PCR product; R, Rsal digestion; $\mathrm{H}$, Hinfl digestion. T, F, C, A, P and NI represent the species Trichophyton, Fusarium, Candida, Aspergillus, Penicillium and non-identified species, respectively. Numbers in parentheses are the sample numbers in Table 3. Samples 23, 26, 61 and 72 are mixed infections. Weak Candida spp. DNA fragments in sample 61 are indicated by an asterisk.
21/29 cases where this fungus grew in culture. In one case, $T$. mentagrophytes type I (Ninet et al., 2003), or T. krajdenii (Kane et al., 1992; Summerbell et al., 1999), was identified by sequencing (sample 22). In samples 23-28 it was not possible to interpret the sequencing results and examination of the trace files led to a suspicion of mixed infections.

The 330 bp Trichophyton spp. PCR amplicon contained a unique HinfI restriction site, whilst that of Fusarium spp. contained a unique RsaI site (Fig. 1). Therefore, separate HinfI and RsaI restriction digestions of amplified DNA allowed a quick differentiation of Fusarium spp. from Trichophyton spp. (Fig. 2). In the six cases where sequencing results were not interpretable (samples 23-28), RFLPs confirmed the presence of two different $330 \mathrm{bp}$ fragments in the PCR product and allowed us to identify Trichophyton spp. (Fig. 2). In conclusion, the results obtained from RFLPs and sequencing of PCR products correlated with the results of cultures from the same nail samples when Fusarium spp. or Trichophyton spp. were isolated. In two cases (samples 50 and 51), Fusarium sp. was considered to be a contaminant, rather than the aetiological agent.

In a second step, the PCR/sequencing/RFLP assay was used for tentative identification of the infecting fungi in 59 nail samples (samples 53-111; Table 3) from which neither dermatophytes nor Fusarium spp. were obtained in culture. Dermatophytes and Fusarium spp. were revealed by sequencing in 16 and 4 cases, respectively. In addition, Scopulariopsis brevicaulis and species of Acremonium, Aspergillus, Penicillium, Alternaria, Curvularia, Mucor and Candida were identified apparently as single infectious agents of onychomycosis (Table 3). In particular, Aspergillus flavus and Aspergillus versicolor were identified three and four times, respectively. When Penicillium spp. and Alternaria spp. were identified in culture, PCR sequencing most often revealed the presence of a different fungus. In these cases, Penicillium spp. and Alternaria spp. were considered to be contaminants.
RsaI and HinfI RFLPs were performed with all PCR products in an attempt to circumvent sequencing in further analysis (Fig. 2). RFLP allowed a quick distinction of Trichophyton spp. from NDF and Candida spp. However, Fusarium spp. and Candida spp. as well as Aspergillus spp. and Penicillium spp. showed identical band patterns (Figs 1 and 2). Therefore, sequencing remains the gold standard for identification of the species involved in onychomycosis. In addition, rare infecting moulds and possible new aetiological agents of onychomycosis can only be determined with certainty after sequencing. RsaI and HinfI RFLPs were useful to show clearly the presence of mixed infections when non-interpretable sequencing trace files were obtained in 13 of the 111 cases examined (12\%) (Fig. 2). We distinguished Candida spp. from Fusarium spp. in mixed infections using specific primers. DNA amplification using the primers CAND and LSU2 amplified a 230 bp 28 S rDNA fragment specific for Candida spp. (data not shown).

PCR identification failed in nine cases among the 111 investigated ( $8 \%)$. Retrospective investigation revealed that these results were from samples where very little nail material was available and where few fungal elements were observed.

\section{Prevalence of NDF in onychomycosis}

Direct identification of fungi in nail samples showed that the prevalence of NDF in onychomycosis is high. The majority of Fusarium spp. and Scopulariopsis brevicaulis and $\sim 50 \%$ of Aspergillus spp. identified in culture were shown to be the aetiological agent. Furthermore, in 43 samples (samples 69-111; Table 3) where moulds were identified other than the aforesaid fungi ( $60 \%$ of positive samples; Table 2 ), NDF were found 18 times as the sole fungus (42\%). Therefore, in our laboratory, we estimate that the frequency of onychomycosis with NDF is $\sim 30 \%$, not including mixed infections. Statistical analysis, based on results from cultures, varies significantly (Summerbell et al., 2005). For example, 3·3\% 
of NDF onychomycoses have been reported in Canada (Summerbell et al., 1989); in contrast, NDF appeared to be more prevalent than dermatophytes in onychomycoses in a geriatric population in the USA (Scherer et al., 2001). During the preparation of this manuscript, an article was published presenting PCR identification of T. rubrum and other moulds in onychomycosis from Bulgaria and Greece (Kardjeva et al., 2006). NDF were detected in only $4 \%$ of infections among 181 positive nail specimens. Scopulariopsis brevicaulis, Fusarium spp. and Aspergillus nidulans were only detected six times, twice and once, respectively.

\section{Conclusions}

PCR methods may provide significant benefits in the rapid diagnosis of onychomycosis. First, NDF can be identified with certainty as the aetiological agents of onychomycosis and discriminated from dermatophytes as well as from transient contaminants. This is particularly relevant as moulds causing onychomycosis are not responsive to certain antifungal drugs in patients (Tosti et al., 2000; Gupta et al., 2001b). Secondly, identification of the infecting agent can be obtained in $24 \mathrm{~h}$ with RFLP or $48 \mathrm{~h}$ with sequencing, whereas results from fungal cultures can take 1-3 weeks; thus this allows selective treatment to be initiated sooner. The costs of a DNA extraction, a PCR and a sequencing reaction are approximately $€ 2, € 1$ and $€ 5$, respectively. For comparison, the cost of a culture is approximately $€ 2$, but there is a frequency of negative fungal results of $40 \%$ when direct nail mycological examination is positive (Table 2). The simplicity, reliability and high NDF frequency support the use of the PCR/ sequencing/RFLP assay reported in the present study, provided that enough nail material is collected by the clinician. Increased pricing of laboratory analyses should always be considered against the high cost of treatment of onychomycoses (more than $€ 1000$ ).

\section{ACKNOWLEDGEMENTS}

We thank Dr Bertrand Favre, Dr Lee Applegate and Dr Derry K. Mercer for critical review of the manuscript and assistance with the English and Giancarlo Tomio and Michael Spörri (Synergene Biotech GmbH) for helpful discussion and technical assistance. This work was supported by the Swiss National Foundation for Scientific Research, grant 3100105313/1.

\section{REFERENCES}

Baek, S.-C., Chae, H.-J., Houh, D., Byun, D.-G. \& Cho, B.-K. (1998). Detection and differentiation of causative fungi of onychomycosis using PCR amplification and restriction enzyme analysis. Int J Dermatol 37, 682-686.

Baudraz-Rosselet, F., Monod, M., Porchet, S. \& Frenk, E. (1992). Retrospective study of the efficacy of two methods of microscopical examination in dermatological mycology. J Mycol Med 2, 148-150.

Chabasse, D. (2004). Epidémiologie et étiologie des onychomycoses. In Onychomycoses, pp. 1-35. Edited by R. Baran \& G. E. Piérard. Paris: Masson.

de Hoog, G. S., Guarro, J., Gené, J. \& Figueras, M. J. (2000). Atlas of Clinical Fungi, 2nd edn. Utrecht: Centrallbureau voor Schimmelcultures.
English, M. P. (1976). Nails and fungi. Br J Dermatol 94, 697-701. Garcia-Effron, G., Gomez-Lopez, A., Mellado, E., Monzon, A., Rodriguez-Tudela, J. L. \& Cuenca-Estrella, M. (2004). In vitro activity of terbinafine against medically important non-dermatophyte species of filamentous fungi. J Antimicrob Chemother 53, 1086-1089.

Gupta, A. K., Cooper, E. A., MacDonald, P. \& Summerbell, R. C. (2001a). Utility of inoculum counting (Walshe and English criteria) in the clinical diagnosis of onychomycosis caused by nondermatophytic filamentous fungi. J Clin Microbiol 39, 2115-2121.

Gupta, A. K., Gregurek-Novak, T., Konnikov, N., Lynde, C. W., Hofstader, S. \& Summerbell, R. C. (2001b). Itraconazole and terbinafine treatment of some nondermatophyte molds causing onychomycosis of the toes and a review of the literature. J Cutan Med Surg 5, 206-210.

Kane, J., Scott, J. A., Summerbell, R. C. \& Diena, B. (1992). Trichophyton krajdenii sp. nov. an anthropophilic dermatophyte. Mycotaxon 45, 307-316.

Kardjeva, V., Summerbell, R., Kantardjiev, T., DevliotouPanagiotidou, D., Sotiriou, E. \& Graser, Y. (2006). Forty-eighthour diagnosis of onychomycosis with subtyping of Trichophyton rubrum strains. J Clin Microbiol 44, 1419-1427.

Machouart-Dubach, M., Lacroix, C., Feuilhade de Chauvin, M., Le Gall, I., Giudicelli, C., Lorenzo, F. \& Derouin, F. (2001). Rapid discrimination among dermatophytes, Scytalidium spp., and other fungi with a PCR-restriction fragment length polymorphism ribotyping method. J Clin Microbiol 39, 685-690.

Menotti, J., Machouart, M., Benderdouche, M., Cetre-Sossah, C., Morel, P., Dubertret, L., Derouin, F., Feuilhade De Chauvin, M. \& Lacroix, C. (2004). Polymerase chain reaction for diagnosis of dermatophyte and Scytalidium spp. onychomycosis. Br J Dermatol 151, 518-519.

Mock, M., Monod, M., Baudraz-Rosselet, F. \& Panizzon, R. G. (1998). Tinea capitis dermatophytes: susceptibility to antifungal drugs tested in vitro and in vivo. Dermatology 197, 361-367.

Monod, M., Baudraz-Rosselet, F., Ramelet, A. A. \& Frenk, E. (1989). Direct mycological examination in dermatology: a comparison of different methods. Dermatologica 179, 183-186.

Ninet, B., Jan, I., Bontems, O., Léchenne, B., Jousson, O., Panizzon, R., Lew, D. \& Monod, M. (2003). Identification of dermatophyte species by $28 \mathrm{~S}$ ribosomal DNA sequencing with a commercial kit. J Clin Microbiol 41, 826-830.

Scherer, W. P., McCreary, J. P. \& Hayes, W. W. (2001). The diagnosis of onychomycosis in a geriatric population: a study of 450 cases in South Florida. J Am Podiatr Med Assoc 91, 456-464.

Summerbell, R. C., Kane, J. \& Kradjen, S. (1989). Onychomycosis, tinea pedis and tinea manuum caused by non-dermatophytic filamentous fungi. Mycoses 32, 609-619.

Summerbell, R. C., Haugland, R. A., Li, A. \& Gupta, A. K. (1999). rRNA gene internal transcribed spacer 1 and 2 sequences of asexual, anthropophilic dermatophytes related to Trichophyton rubrum. J Clin Microbiol 37, 4005-4011.

Summerbell, R. C., Cooper, E., Bunn, U., Jamieson, F. \& Gupta, A. K. (2005). Onychomycosis: a critical study of techniques and criteria for confirming the etiologic significance of nondermatophytes. Med Mycol 43, 39-59.

Tosti, A., Piraccini, B. M. \& Lorenzi, S. (2000). Onychomycosis caused by nondermatophytic molds: clinical features and response to treatment of 59 cases. J Am Acad Dermatol 42, 217-224.

Turin, L., Riva, F., Galbiati, G. \& Cainelli, T. (2000). Fast, simple and highly sensitive double-rounded polymerase chain reaction assay to detect medically relevant fungi in dermatological specimens. Eur J Clin Invest 30, 511-518. 